\title{
EXPERIMENTAL MEASUREMENT AND NUMERICAL MODELING OF CAVITATING FLOW IN CONVERGING-DIVERGING NOZZLE
}

\section{INTRODUCTION}

Swirling flows are very important in many industrial applications, especially in those cases, when mixing needs to be enhanced (like in swirl combustors) or in case, where centrifugal forces can be utilized for example for separation of dust particles (like in cyclone separators). On the other hand there are a lot of situations, when the increased rate of mixing also increases dissipation or leads to instability of the flow. It is particularly the case of Francis turbine operation outside of the best efficiency point.

Strongly swirling coherent vortical structure appears, often filled with saturated vapour. This phenomenon is well known as vortex rope (or cavitating vortex rope) in hydraulic machines theory. Efficiency drop, severe pressure pulsations and structural vibrations of the machine are typical features that accompany appearance of the vortex rope. Form of the vortex rope depends on the operational regime of the turbine. Spiraling vortex resulting from the spiral vortex breakdown appears for partial load operation (see Figure 1 ), whereas huge straight vortical structure is characteristic for the full load operation (see Figure 2).

Swirling flows are of immense interest for several decades, starting with research of Peckham and Atkinson [6] in the fifties of the last century, through experimental works of Sarpkaya [8], analytical approaches of Benjamin [2], Leibovich [4] to thorough description of Alekseenko et al [1]. An overview of the vortex breakdown research (not complete, but quite broad) can be found in [5].

\footnotetext{
- Pavel Rudolf, Brno University of Technology, Faculty of Mechanical Engineering, Technická 2896/2, Brno 61669, rudolf@fme.vutbr.cz

Martin Hudec, Brno University of Technology, Faculty of Mechanical Engineering, Technická 2896/2, Brno 61669, hudec@fme.vutbr.cz

Pavel Zubík, Brno University of Technology, Faculty of Civil Engineering, Veveř́, Brno 61669, zubik.p@fce.vubr.cz

David Štefan, Brno University of Technology, Faculty of Mechanical Engineering, Technická 2896/2, Brno 61669, y101274@stud.fme.vutbr.cz
}

This is an Open Access article distributed under the terms of the Creative Commons Attribution License 2.0, which permits unrestricted use, distribution, and reproduction in any medium, provided the original work is properly cited. 


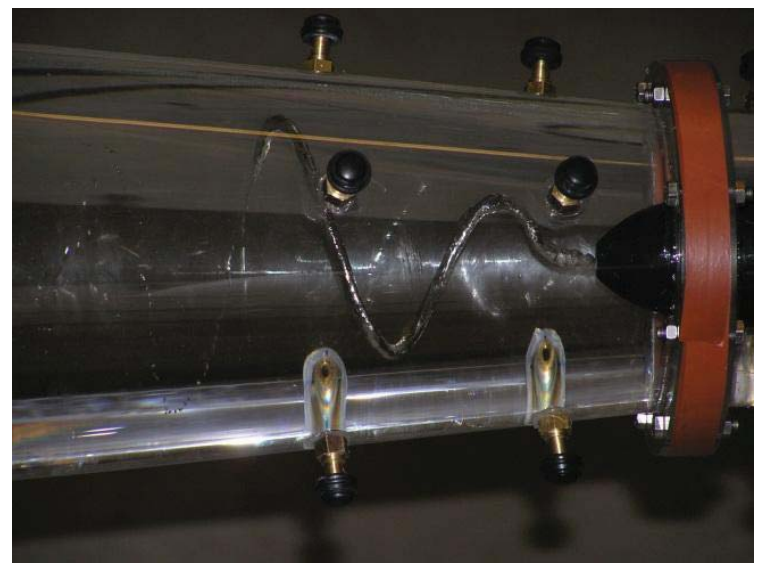

Figure 1: Spiraling cavitating vortex rope (partial load operation) [7]

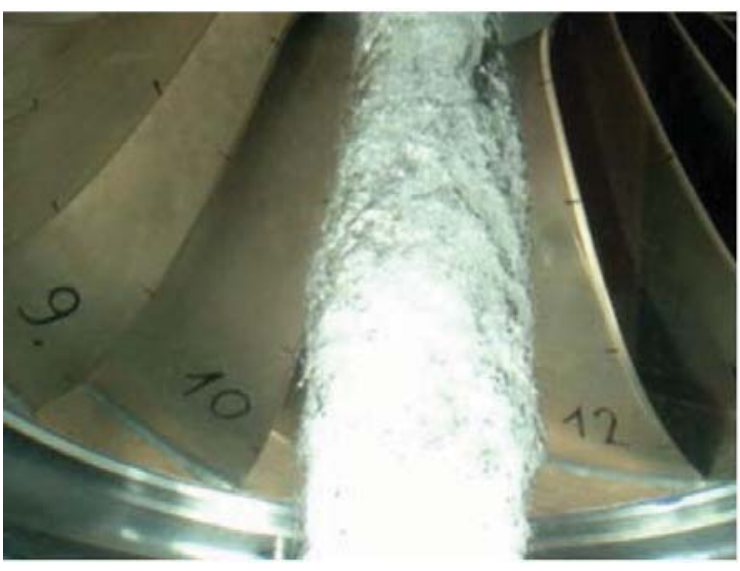

Figure 2: Straight cavitating vortex rope (full load operation) [3]

Despite the extensive research effort most of the very fundamental questions still remain open (e.g. origin of the vortex breakdown, analytical approach to finding the frequency of the vortex rope rotation, etc.).

\section{VELOCITY AND PRESSURE DISTRIBUTION}

A balance of the pressure and centrifugal forces is established, when swirling flow is present. A simple view of this situation for case of inviscid fluid is provided by radial component of the Euler equation:

$$
\frac{\partial \mathrm{p}}{\partial \mathrm{r}}=\rho \frac{\mathrm{v}_{\varphi}^{2}}{\mathrm{r}}
$$

Tangential velocity profile can be approximated by Lamb vortex, which is a viscous correction of the Rankin vortex.

$$
\mathrm{v}_{\varphi}=\frac{\Gamma}{2 \pi \mathrm{r}}\left(1-\exp \left(-\frac{\mathrm{r}^{2}}{\mathrm{r}_{\mathrm{c}}^{2}}\right)\right)
$$

where $\Gamma$ is circulation of the velocity profile. A formula in terms of $v_{m}$ (maximum velocity of the profile) and effective radius $r_{e}$ was derived by Alekseenko et al. [1]:

$$
\mathrm{v}_{\varphi}=\mathrm{v}_{\mathrm{m}} \frac{1.39}{\left(\mathrm{r} / \mathrm{r}_{\mathrm{e}}\right)}\left(1-\exp \left(-1.26 \frac{\mathrm{r}^{2}}{\mathrm{r}_{\mathrm{e}}^{2}}\right)\right)
$$

Introducing equation (3) into equation (1) and integration leads to exponential integrals. Numerical solution provides pressure distribution according to Figure 3.

Solution of equation (3) for Lamb vortex shows pronounced pressure drop in the region of the irrotational core. The minimum pressure is the level of the saturated vapor pressure, when water evaporates and cavitating phase appears. If the pressure is increased (for example by increase of the cross-sectional area) the vapor violently condensates and one phase flow is established again. It will be shown later that tangential velocity profile shape, namely location of the velocity maximum and 
magnitude of the maximum velocity are decisive for the shape of the cavitating vortical structure.

It should be noted that in 3D the situation is more complicated, since also the axial velocity profile is influenced by rotation of the liquid. This situation is described by Batchelor vortex $[1,5]$.

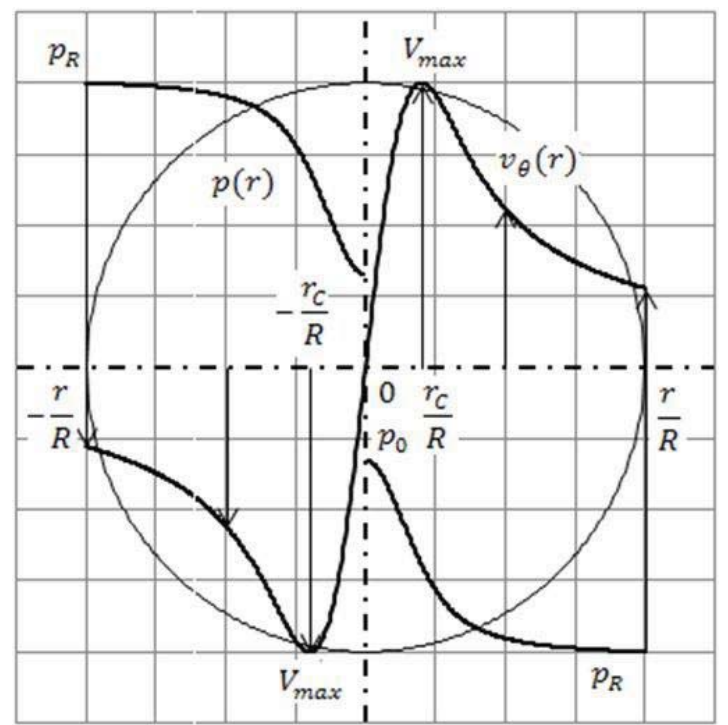

Figure 3: Velocity and pressure distribution within Lamb vortex

\section{EXPERIMENTAL CIRCUIT AND VELOCITY MEASUREMENTS}

An experimental circuit was built from plastic pipes DN50, see Figures 4,5 . Water is circulated by centrifugal pump controled by frequency convertor. The test section is a converging-diverging (CD) nozzle made of polished plexiglass. Circuit enables to measure flow rate, pressure pulsations in several stations, water temperature and amount of the dissolved oxygen.

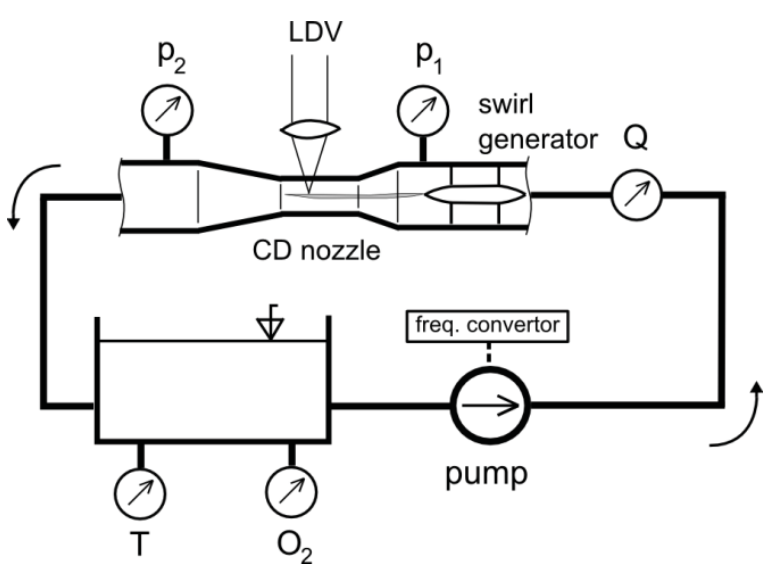

Figure 4: Scheme of the experimental circuit

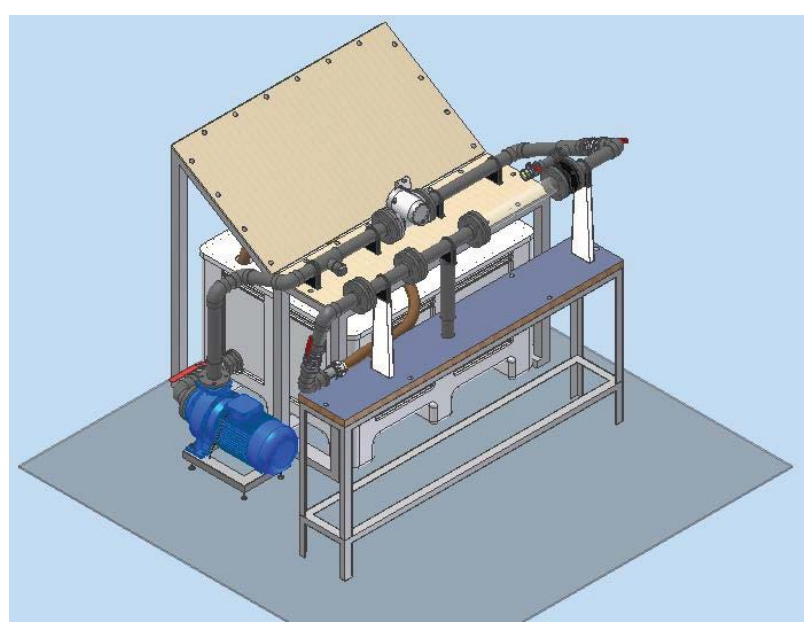

Figure 5: View of the experimental circuit 
Swirl at the inlet of the CD nozzle is achieved by swirl generator, see Figure 6 . Generator has 10 fixed blades with relatively long narrow channels to prevent flow separations along the blade surface for a broad range of operating regimes. CFD simulation proved that almost identical velocity angles are provided by the generator for flow rates between 4 and $13 \mathrm{l} / \mathrm{s}$ (see Figure 7).

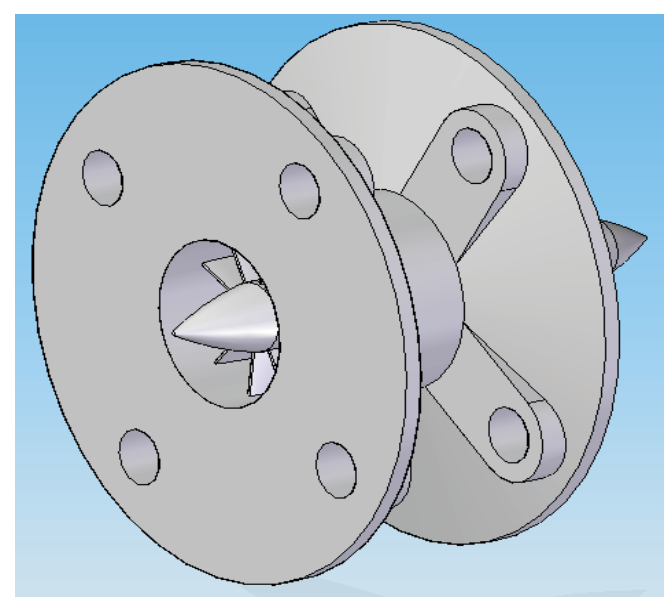

Figure 6: Swirl generator

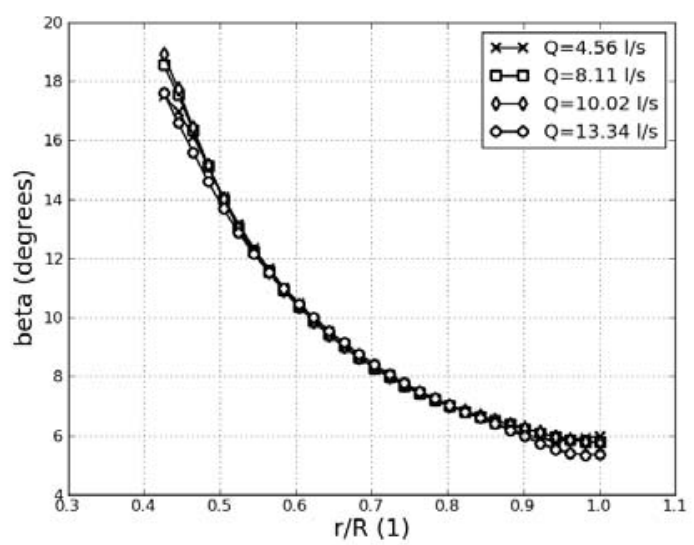

Figure 7: Angle of the velocity vector behind the swirl generator

Axial and circumferential (tangential) components of the velocity vector were measured using Laser Doppler Velocimetry (LDV). Argon laser Ion Laser Technology Model 5500A with output $300 \mathrm{~W}$ and DANTEC processing equipment were applied. Reynolds number based on the bulk velocity $\mathrm{w}$ in the throat of $\mathrm{CD}$ nozzle and the throat diameter was ranging from 200000 to 600000 . From 4000 to 20000 thousand samples were gathered for one point of measurement to compute the mean velocity component (data rate was between 1500 and 4000 for axial velocity component and about one order lower for circumferential velocity component). Plane surface was milled and polished on the outer wall of the converging-diverging nozzle to minimize the laser beam refraction.

Velocity measurements were carried in the middle of the CD nozzle. It has to be stressed that non-cavitating regime is only for rather low flow rates (up to $6 \mathrm{l} / \mathrm{s}$ ). Straight cavitating vortical structure appears for higher flow rates. The phase interface between water and saturated vapor serves like impermeable barrier for the laser beam and disqualifies reliable measurements. Experimentally obtained velocity profiles were used for CFD validation.

\section{CFD MODELING}

Whole circuit beginning with straight pipe behind the pump, elbow and swirl generator was modeled to obtain inlet velocity profiles into the CD nozzle. These simulations relied on realizable k-epsilon model, because of the non-complicated nature of the flow in these hydraulic elements.

Model of the test section itself comprised hub of the swirl generator, CD nozzle and straight, 5 diameters long, pipe to prevent ill posed boundary condition at the outlet. Mesh sensitivity analysis was carried out to find the optimum size of the mesh and distribution of the finite volumes. It was concluded that clustering of the volumes along 
the axis is extremely important for prediction of the velocity peaks and consequently pressure minima in this region. The resulting mesh size is around 5 milion finite volumes. Several approaches, namely realizable k-epsilon model, Reynolds stress model (RSM) and large eddy simulation (LES) were employed for modeling of the turbulent one.phase flow. Non-equillibrium wall functions are applied on the walls. Large eddy simulation uses the dynamic version of Smagorinski model for computation of the subgrid scale turbulence. Velocity fluctuations are provided by spectral synthesizer.

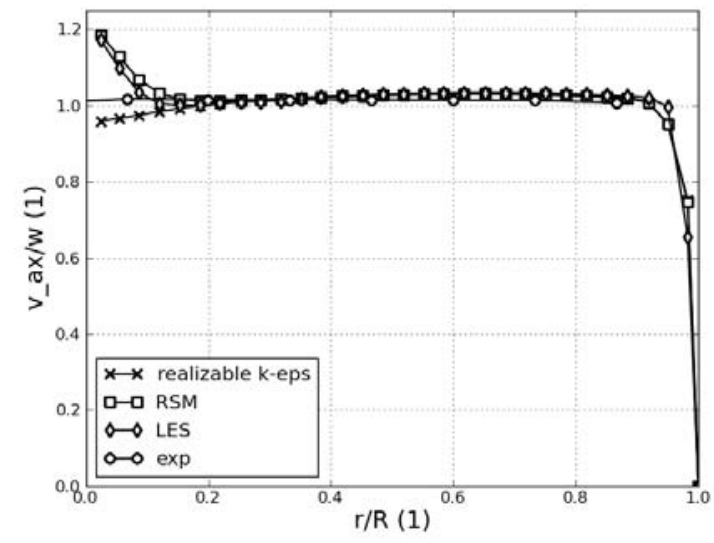

Figure 8: Axial velocity profile in the middle section of the $C D$ nozzle, $Q=4,56 \mathrm{l} / \mathrm{s}$, non-cavitating regime

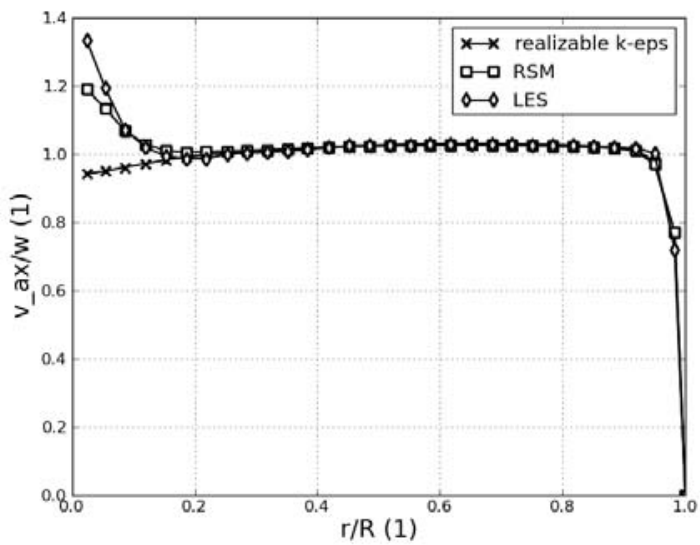

Figure 10: Axial velocity profile in the middle section of the $C D$ nozzle, $Q=10,28$ $\mathrm{I} / \mathrm{s}$, cavitating regime

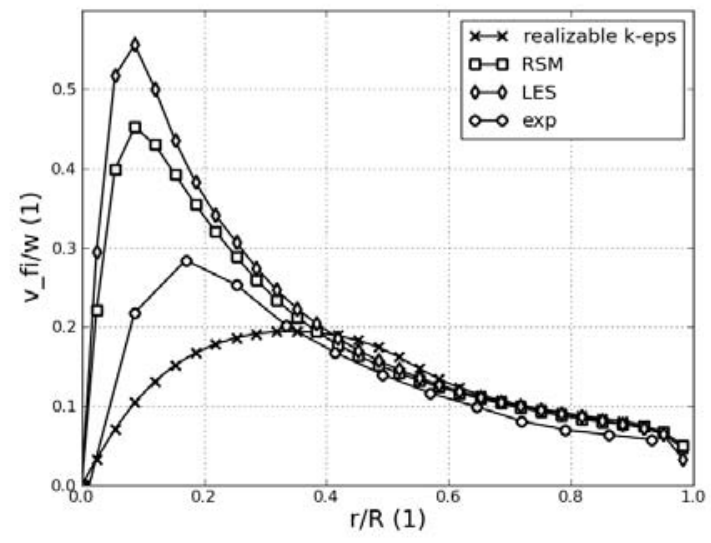

Figure 9: Tangential velocity profile in the middle section of the $C D$ nozzle, $Q=4,56$ $\mathrm{I} / \mathrm{s}$, non-cavitating regime

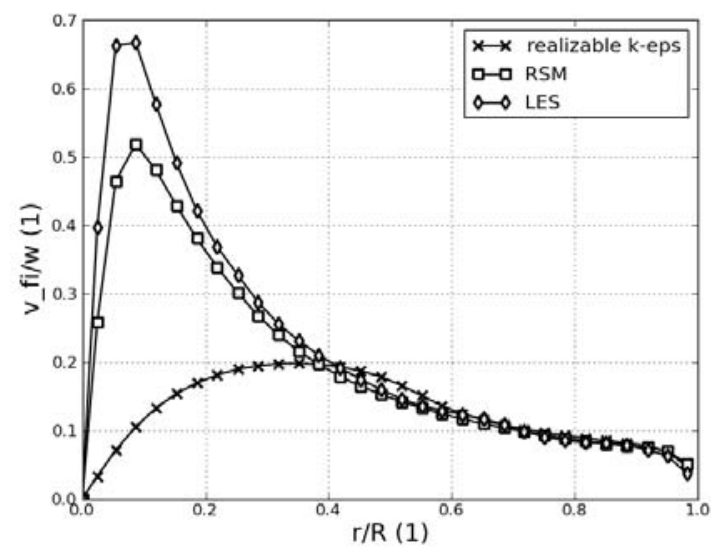

Figure 11: Tangential velocity profile in the middle section of the $C D$ nozzle, $Q=10,28$ $\mathrm{l} / \mathrm{s}$, cavitating regime

The simulations were carried out for several flow rates ( $Q=4,56 ; 10,28 ; 13 \mathrm{l} / \mathrm{s})$. The first one corresponds to non-cavitating regime, whereas the other two to developed cavitating vortical structure along the axis of the nozzle. The first regime enables comparison of the measured and computed velocity profiles.

Figures 8,9 honestly show that none of the models is able to predict correct velocity profile. Especially the case of tangential velocity component is striking. Realizable k - 
epsilon model underpredicts maximum velocity and significantly overpredicts size of the vortex core. On the other hand both RSM and LES calculate too high tangential velocity peak (about twice higher than experiment) and relatively very narrow vortex core. Similar behavior is observed also for higher flow rates (see Figures 10, 11).

Axial velocity profiles are also affected by CFD model selection. Experimental data suggest more or less flat profile, while realizable k-epsilon model predicts trough of the axial velocity component in the vicinity of the axis and both RSM and LES show axial velocity peak in this region. It means that completely different behavior is computed (wake-like vs. jet-like velocity profile, see [4, 5]).

Another batch of simulations focused on higher flow rates $(10,28$ and $13 \mathrm{l} / \mathrm{s})$. No reliable velocity measurements were obtained for those regimes, because caviting phase was present in the centre of the $C D$ nozzle. However direct comparison is enabled by visualizations of the cavitating flow. Absolute static pressures measured behind the $C D$ nozzle were prescribed on the outlet of the computational domain to observe the regions of the saturated vapor pressure. Magnitude of the vapor pressure was assessed experimentally.

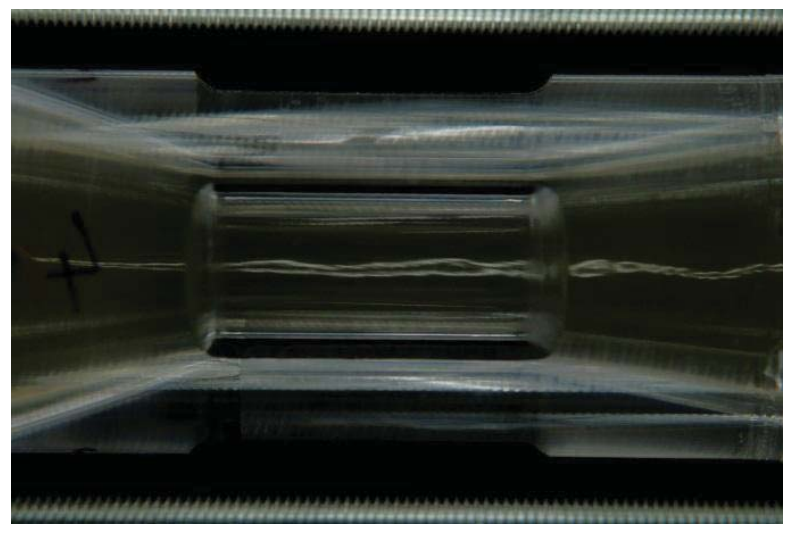

Figure 12: Cavitating vortical structure for $\mathrm{Q}=10,28 \mathrm{l} / \mathrm{s}$ (experimental visualization)

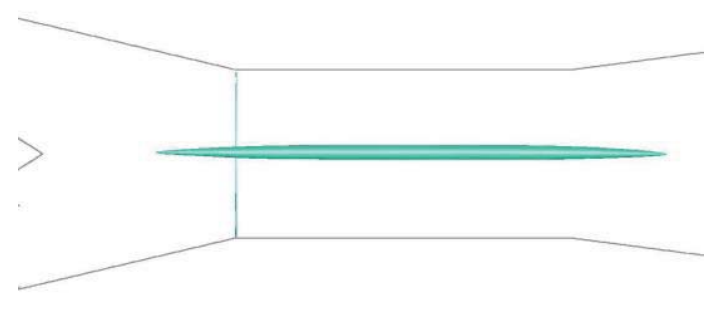

Figure 14: Contour of the vapour pressure $\mathrm{Q}=10,28 \mathrm{l} / \mathrm{s}$, (RSM)

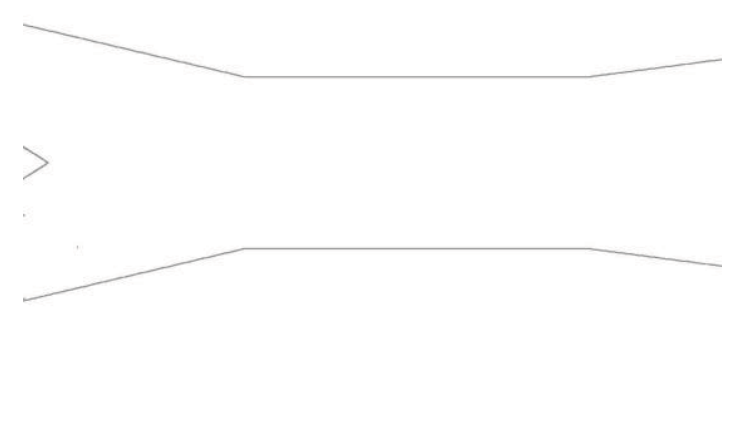

Figure 13: Contour of the vapour pressure $\mathrm{Q}=10,28 \mathrm{l} / \mathrm{s}$, (realizable k-epsilon)

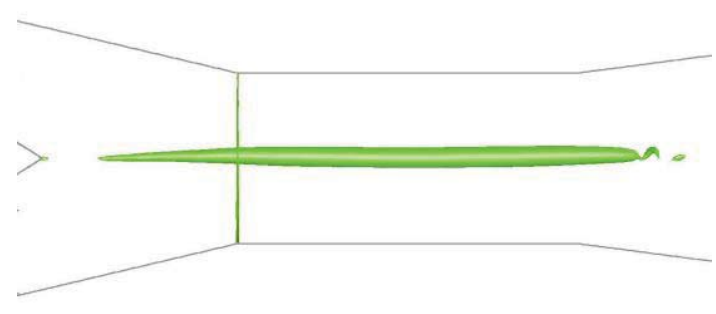


Figures 12 to 15 show very good agreement between the cavitating vortical filament and contours of the saturated vapor pressure for RSM and LES simulations. It is remarkable that no region on the pressure level of liquid evaporation appears for realizable k-epsilon model (the minimum static pressure along the axis is twelve times higher than saturated vapor pressure). RSM predicts quite well the time averaged behavior of the vortical structure, but is not able, even when unsteady term is inluded, to mimic onset of instability at the inlet of the diverging part. LES proves to be superior, but at the cost of extremely high computational expanses (unsteady simulation with time step $1.10^{-5} \mathrm{~s}$ ).

Suitability of the LES approach is confirmed also for the higher flow rate (see Figures 16, 17).

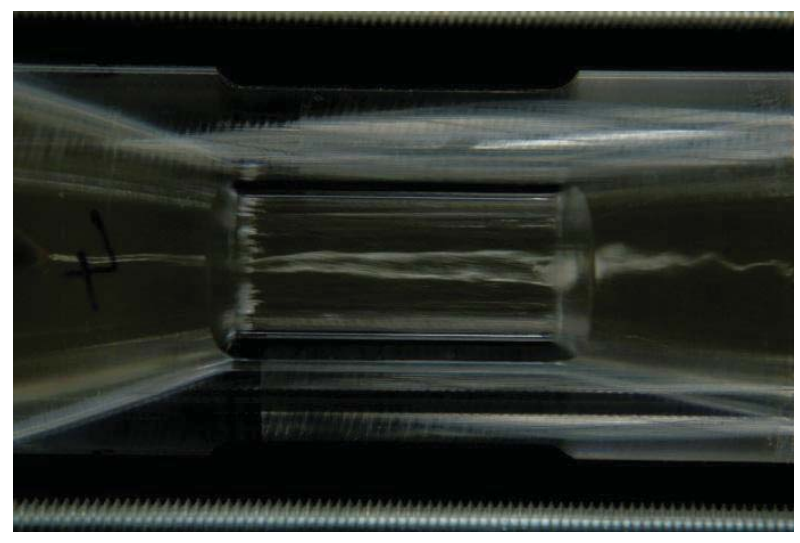

Figure 16: Cavitating vortical structure for $\mathrm{Q}=13 \mathrm{l} / \mathrm{s}$ (experimental visualization)

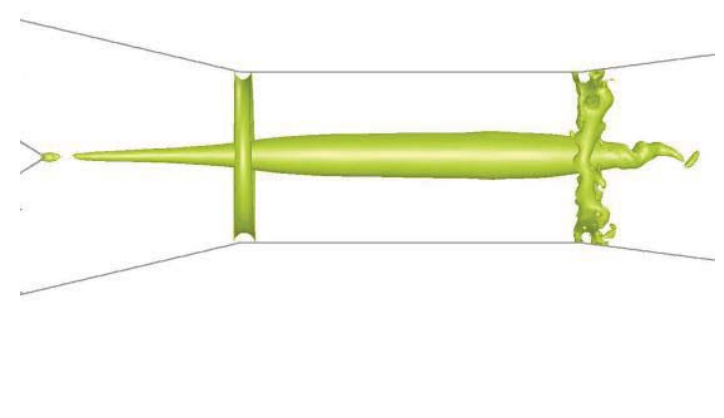

Figure 17: Contour of the vapour pressure $\mathrm{Q}=13 \mathrm{l} / \mathrm{s},($ LES)

Large eddy simulation also describes the desintegration of the vortex at the inlet of the diverging section, where spiral vortex breakdown occurs (see Figures 18, 19).
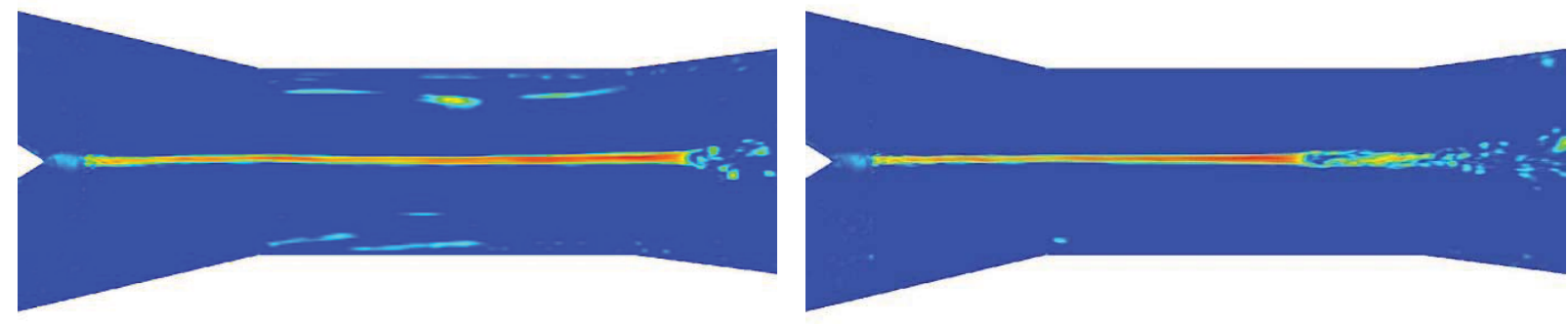

Figure 18: Contours of normalized Qcriterion, $\mathrm{Q}=10,28 \mathrm{l} / \mathrm{s}$, (LES)
Figure 19: Contours of normalized Qcriterion, $\mathrm{Q}=13 \mathrm{l} / \mathrm{s}$, (LES) 


\section{Conclusion}

Computational simulations using more complex models compared quite well with visualizations of the cavitating flow. On the other hand poor agreement was obtained as for the velocity profiles. This result will need further investigation and clarification.

Although rather contradictory results were obtained, several conclusions can be drawn:

1. Strong coupling exists between the particular velocity components and between the velocity and pressure fields in highly swirling flows. Proper resolving of the velocity profile in the vicinity of the axis is necessary to obtain correct pressure field in this region.

2. Realizable k-epsilon model, as a representative of eddy viscosity models, is not suitable for simulations of highly swirling flows. Swirling flows feature strong anisotropy of turbulence, where vorticity dynamics plays significant role. Therefore more sophisticated approaches are necessary to capture the true nature of the flow.

3. Performance of Reynolds stress model and large eddy simulation is almost identical, if only time averaged characteristics are searched. However RSM is not able to describe the unsteady behavior with spiral vortex breakdown and rich cascade of vortices, which originate during vortical structure desintegration.

Future experimental research will be focused on design of an improved circuit, which will enable adjustment of the static pressure level using vacuum pump. Computational simulations will be directed towards incorporating the cavitation model based on simplified Rayleigh-Plesset equation.

\section{ACKNOWLEDGEMENT}

Czech Science Foundation is gratefully acknowledged for support of the research under project No. 101/09/1715 "Cavitating vortical structures induced by rotating liquid".

\section{REFERENCES}

[1] Alekseenko, S. V.; Kuibin, P. A.; Okulov, V. L.: Theory of Concentrated Vortices: An Introduction, 1 ed. Springer, 2007.

[2] Benjamin, B. T. Theory of the vortex breakdown phenomenon. Journal of Fluid Mechanics, 14, 593-629, 1962.

[3] Koutník, J., Nicolet, C, Schohl, G.A., Avellan, F.: Overload Surge Event in a Pumped-Storage Power Plant, Proceedings of 23rd IAHR Symposium, Yokohama, 2006.

[4] Leibovich, S.: The structure of vortex breakdown. Annual Review of Fluid Mechanics, 10, 221-246, 1978.

[5] Lucca-Negro, O., and O'Doherty, T.: Vortex breakdown: a review. Progress in Energy and Combustion Science, 27, 431-481, 2001.

[6] Peckham, D. H., and Atkinson, S.: Preliminary results of low speed wind tunnel tests on gothic wing of aspect ratio 1.0. Tech. rep., 1957.

[7] Rudolf, P.: Connection between inlet velocity field and diffuser flow instability. Applied and Computational Mechanics, 3, No 1, 177-184, 2009.

[8] Sarpkaya, T.: Effect of adverse pressure gradient on vortex breakdown. AIAA Journal, 12, No5, 602-607, 1974. 